\title{
Research on College English Teaching under the Concept of Cultural Experience
}

\author{
Hong Cai \\ Xi'an Peihua University, Xi'an, 710125, China
}

Keywords: College English teaching, Cultural experience, Intercultural communication

\begin{abstract}
College English class not only brings about the English knowledge to the students, but also can cultivate the cultural interest, cultural cognition and cultural habits of student by the means of cultural experience. In the implementation process of culture experience teaching of the college English class, teachers should penetrate cultural experience knowledge, create cultural experience environment and strengthen cultural experience practice. Only in this way can we promote the smooth development of college English teaching under the concept of cultural experience.
\end{abstract}

\section{Introduction}

In the traditional foreign language teaching in China, there has been a light focused on language cultural phenomenon; especially in college English class, the main content on the vocabulary and grammar knowledge has been regarded as the teaching; and for cultural knowledge introduction is less and less. The giant in the language of historical events, customs and other characters introduced only as background knowledge are introduced, even in the teaching not essential; it makes learners after rote learning, but not to use appropriate language to express their own thoughts; after memorizing grammar vocabulary knowledge however, the inability to use English with foreigners on a particular occasion of effective communication. The cultivation of foreign language communicative competence has been explicitly included in the college English syllabus. The cultivation of foreign language talents is a kind of compound talents with a solid foundation of English language and broadcasting, and can skillfully apply to various occasions. Culture teaching and language teaching has the same important position; in English class, not only stimulate learners interest in learning culture teaching, provide rich and colorful context for language teaching, but also promote the improvement of language learning and communicative competence of foreign language learners; language teaching and culture teaching, the complementary integration. The process of cultural experience includes two aspects: psychological experience and practical experience. In the course of a certain experience, the psychological experience and the practical experience are integrated. The college English teaching in China defines the cultural experience as the students' understanding of foreign culture on the basis of their own cultural background. Therefore, in this paper, the cultural experience refers to the cultural theme for the teaching content and teaching mode to increase the proportion of students in the learning process of active experience to better understand the cultural connotation of the language.

\section{Significance of Cultural Experience Applied in the College English Teaching}

Cultural Interest Cultivation. In English teaching, we can recommend some excellent English literature to the students. Some of the information to enable students to contact the original English, encourage students to read extensively and the cultural phenomenon for books, newspapers and magazines, and encourage them to contact the original English film, literature and tourism programs and so on. We teachers should have a clear understanding, that is, in the process of cultural infiltration, only to give full play to their own subjective initiative, in order to truly achieve the desired results of cultural transmission. Some students put the listening class as a sleeping and relaxing time. As we all know that the training of listening skills and improve the most effective way is to reach a qualitative leap, is strengthening repeatedly received active listening information, once thought of Fugue, will go 
farther and farther, to keep up with the rhythm and content, be sleepy straws. The teacher called the English in the listening class a lullaby. In a limited period of time in the classroom, it is not feasible to use frequently asked students to answer questions in order to remind and force them to stay awake all the time. Therefore, teachers need to find some careful, can cause students interest in cultural knowledge to each content under the regulation of the atmosphere in the blues, absent-minded. They enable students to understand the language of the country's history, geography, literature, education, customs, customs and other aspects of cultural knowledge. This can not only enrich the cultural background of the students, but also enhance the students' interest in learning and improve the ability of learning English.

Cultural Cognition Cultivation. The comprehensive application ability of English language knowledge is one of the components of students' cross cultural cognitive ability, which is the ultimate goal of College English teaching. Cross cultural cognitive competence is essential for students to succeed in intercultural communication. It refers to the ability to communicate effectively with people of different cultural backgrounds. Relates to two kinds of conversion between different language and cultural thinking, most of the students in learning English, especially for science and engineering students are not familiar with the cultural background of English, often only can translate literal and grammatical meaning, but the deeper meaning in the article cannot grasp. In the teaching of science and engineering students, the author finds that the students of science and engineering know little about the cultural knowledge, which limits their acquisition of the content of the text. In this case, the teacher must supplement the relevant cultural background to guide and help the students to solve the difficulties. Cognitive factor refers to the students' cross-cultural awareness, that is, people's understanding of their own culture and foreign culture on the basis of the formation of changes in the world's perception, while reasonably adjusting their language behavior patterns. Teachers can promote the cultivation of students' intercultural awareness and cognitive ability through the application of cultural experience in college English teaching. The theme of the relationship between the name and the character. But the list of so many of our students Chinese is only heard but its meaning without the concept of Western names, resulting in the process of reading is the name of English dazzled, still confused after reading. The interpretation of this article must guide the cultural background of the person and the name. At the same time, students are more familiar with the Chinese name to compare, so that students understand more comprehensive and clear.

Cultural Habits Cultivation. Cross cultural habits of the ability of students to use English communication strategies flexibly, actively establish communication with each other, and the conversation process of reasonable control, is the ultimate embodiment of the comprehensive application of knowledge of English ability of the students. If the teacher is to make students form the habit of cross-cultural ability, need to cross cultural cognitive ability and emotional ability as the basis, through the cultural experience teaching penetration to change students' cultural psychology, strengthen the students to experience the culture, make English knowledge internalization. China students generally used to listen to the teacher often watched in silence What I say goes., teachers, teacher questions, students called up to answer the question of habit not to say yes or no. Teachers in the English-speaking countries feel a great insult to the idea that the students are deliberately contemptuous of the teachers. This is also a misunderstanding between Chinese students and English teachers in the absence of proper communication and understanding. Chinese students often remain silent about the teacher's questions. Teachers in English speaking countries do not know this phenomenon, so the problem arises. English teacher, Chinese students just quietly listen to the English-speaking countries, it is difficult for teachers to active classroom atmosphere, had to speak off the reel, so easy to let the students think that English speaking countries China teachers lack of teaching art, boring classroom teaching often leads to Chinese students by classroom teaching efficiency not to utter a single word, very low, off hire the original intention of teachers in English speaking countries. 


\section{Teaching Strategies of College English under the Concept of Cultural Experience}

Impart Knowledge of Cultural Experience. The traditional mode of college English teaching is the unit teaching. It emphasizes the students' English pronunciation and intonation to be accurate, the English vocabulary to be large, while focusing on training students with the vocabulary, the ability to use vocabulary, enhance the ability to test, usually ignore cultural factors. As a result, teachers become the main body of teaching, students are not in the classroom listening, taking notes, that is, in the classroom to complete a large number of exercises. Although by the way students generally have a solid foundation, and can master the use of the word method, can also carry out English writing, but they do not understand the culture of the countries. Students cannot correctly understand the knowledge of English, use English to communicate more successfully. Therefore, teachers should pay attention to the transformation of teaching mode, the infiltration of cultural knowledge in the process of classroom teaching, and effectively cultivate students' cultural awareness. When students talk with westerners, there are some problems that Chinese people don't care about, but Westerners value it very much. If you do not understand the cultural differences, it is easy to let the two sides in an awkward position in the conversation. Westerners believe that these are their own privacy, cannot be disclosed to outsiders, these require teachers in the classroom teaching process. After a long period of time, the spread of idioms not only embodies the common sense of life, but also accumulated some profound national cultural characteristics. Idioms, due to the influence of the national culture, inevitably reflect the unique thinking and language habits. Idioms, as the essence of language, reflect the historical background, customs and habits of a nation in many ways. Teachers should understand the cultural connotation of the language vocabulary, and teach it to the students, so that students can understand and use English more accurately.

Establish Environment of Cultural Experience. Teachers can actively make use of information technology multimedia courseware, highlighting the cultural theme, or from the Internet to select some of the cultural themes related to the film video. They meet the needs of students' visual information, and guide students to make different interpretations of the visual symbols in movies and videos related to the cultural theme. Students bold imagination and association, to determine the meaning of the community, the cultural implication contained in the analysis of the social and cultural background of the true meaning of the discussion. Finally, the teachers make appropriate evaluation. English cultural knowledge with situational practice experience is helpful to promote students' understanding of cultural knowledge. College English teaching belongs to the cultural experience of experiential teaching cannot do without the teaching situation, teachers in the creation of the cultural context in the process of authenticity, must pay attention to the situation and cultural content of language, context more real, more abundant and profound experience of students. In the process of cultural context, the learners interact with the scene, the learners interact with the learners, and get the cultural knowledge in the interaction. In the aspect of providing cultural information, teachers should combine the content of college English teaching materials to reflect the theme of English culture. Teachers can guide students to pay attention to the culture of English speaking countries by means of video data and written materials. In the course of the situational practice or role playing, the authenticity of the language environment promotes the students to acquire the knowledge of language and culture, and to carry out the cultural experience. The teachers' experience of students need to pay attention to the scene, as the cultural context is true or not affect college students' cultural knowledge level of experience.

Strengthen Practice of Cultural Experience. In the process of guiding students' cultural experience, teachers should pay attention to the lack of clear understanding of the use of English language. In front of the role play, the teacher as the advance organizer to make the students gain the passive psychological experience. Teachers to guide students to carry out active cultural knowledge of practical experience. Teachers make the students' main body status gradually. After the teacher's gradual guidance, the students get familiar with the English language and cultural knowledge, and gradually expand the English cultural knowledge. Taking students as the center is the focus of current education, and the College English teaching should emphasize the students' Autonomous learning. In 
addition to the common knowledge of the students in the classroom, teachers should highlight the students as the main body, prompting students to experience and understand the cultural knowledge in the experience. With the progress of science and technology, students can access to a variety of cultural knowledge through the network, teachers in the classroom to achieve the teaching objectives in a limited amount of time and students want to learn a large amount of cultural knowledge. In view of this situation, teachers can be arranged through the experience of students' autonomous learning tasks, students before class use the Internet to search for information related to the cultural background, so that students in the next classroom learning to experience active cultural knowledge. In addition, the majority of college students from all over the country, there are some differences in the main experience, teachers need to guide students to a meaningful direction. The degree of participation of students in constructivist theory is the key factor to stimulate learning. The cooperative learning between teachers and students, the cooperative learning between students and students. The cooperation can optimize the students' intelligence.

\section{Conclusion}

In a word, language and culture are inseparable. College English teaching should not only teach students knowledge of language, but should also guide students to become the learners and experiencers of English culture. The significance and strategies of the knowledge and ability development under the concept of cultural experience need teachers and scholars to explore in the future.

\section{References}

[1] Huang Qiuyang, Exploration on College English Teaching Based on Cultural Experience [J]. The Science Education Article Collects, 2016(10): 171-172+177.

[2] Sun Wentong, On the College English Teaching Strategy on the Basis of Cultural Experience [J]. Journal of Jilin Agricultural Science and Technology University, 2015, 24(1): 107-109.

[3] Zhang Xiaojuan, Analysis on the Teaching by Cultural Experience in the College English Class [J]. Read and Write Periodical, 2015, 12(5): 22+55.

[4] Zhang Le, On Cultural Experience and University English Culture Teaching [J]. Overseas English, 2011(7): 102-103. 